Supporting Information

\title{
Glutathione-Sensitive Hyaluronic Acid-SS-Mertansine Prodrug with a High Drug Content: Facile Synthesis and Targeted Breast Tumor Therapy
}

Ping Zhong, Jian Zhang, Chao Deng, Ru Cheng*, Fenghua Meng, and Zhiyuan Zhong*

Biomedical Polymers Laboratory, College of Chemistry, Chemical Engineering and Materials Science, Soochow University, Suzhou, 215123, P. R. China.

* Corresponding authors. Tel/Fax: +86-512-65880098, E-mail: rcheng@suda.edu.cn (R. Cheng); zyzhong@suda.edu.cn (Z. Zhong)

Materials. Sodium hyaluronic acid (HA, molecular weight: $35 \mathrm{kDa}$, Shandong Freda Biopharm Co., Ltd.), 2-mercaptoethylamine hydrochloride (98\%, J\&K), 2, 2'-dipyridyl disulfide (98\%, J\&K), 4-(4, 6-dimethoxy-1，3， 5-triazin-2-yl)-4-methyl morpholinium chloride (DMTMM, 98\%, Tokyo Chemical Industry Co., Ltd.), glacial acetic acid (Sinopharm Chemical Reagent Co, Ltd. ), glutathione (GSH, 99\%, Roche), cyanine5 amine hydrochloride $\left(\mathrm{Cy} 5-\mathrm{NH}_{2} \quad \cdot \quad \mathrm{HCl}, \quad 95 \%\right.$, Wuxi UCallM Biotech Co., Ltd.), and $\mathrm{N}_{2}{ }^{\prime}$-deacetyl- ${ }_{2}{ }^{\prime}$-(3-mercapto-1-oxopropyl)- Maytansine (Mertansine DM1, $>98 \%$, Suzhou Brightgene Co., Ltd.) were used as received. Dimethyl sulfoxide was dried by refluxing over anhydrous magnesium sulfate and distilled under reduced pressure before use. 2-(Pyridyldithio)-ethylamine hydrochloride (PDA $\cdot \mathrm{HCl})$ was synthesized as previous report. ${ }^{1}$

Characterization. The chemical structures of polymers were characterized using ${ }^{1} \mathrm{H}$ 
NMR on a Unity Inova 400 spectrometer operating at $400 \mathrm{MHz}$ or Agilent DD2 operating at $600 \mathrm{MHz}$ using $\mathrm{D}_{2} \mathrm{O}$ or $\mathrm{D}_{2} \mathrm{O} / \mathrm{DMSO}_{6}(1: 2, \mathrm{v}: \mathrm{v})$ as a solvent. The hydrodynamic sizes of prodrugs were determined using dynamic light scattering (DLS) at $25{ }^{\circ} \mathrm{C}$ using Zetasizer Nano-ZS (Malvern Instruments) equipped with a $633 \mathrm{~nm}$ He-Ne laser using back-scattering detection.

Synthesis of Cy5-labeled HA-SS-DM1. Briefly, under a nitrogen atmosphere, to a stirred aqueous solution (20 mL, pH 6.5) of HA (60 mg, $0.156 \mathrm{mmol}$ carboxyl group), cyanine5 amine hydrochloride $\left(\mathrm{Cy} 5-\mathrm{NH}_{2} \cdot \mathrm{HCl}, 2.55 \mathrm{mg}, 3.9 \mu \mathrm{mol}\right)$ and 2-(pyridyldithio)-ethylamine hydrochloride (PDA.HCl, $5.2 \mathrm{mg}, 23.4 \mu \mathrm{mol})$ at $35{ }^{\circ} \mathrm{C}$ was added 4-(4, 6-dimethoxy-1, 3, 5-triazin-2-yl)-4-methyl morpholinium chloride (DMTMM, $10 \mathrm{mg}, 36 \mu \mathrm{mol}$ ). After $24 \mathrm{~h}$ reaction, resulting Cy5-HA-SS-Py adduct was extensively dialyzed against deionized (D.I.) water (MWCO 3500) and then lyophilized. Yield: $81 \%$. UV-Vis measurement (UV-Vis spectrophotometer, UH5300, HITACHI, JAPAN) showed that Cy5-HA-SS-Py conjugate had on average one Cy5 molecule per polymer chain. Then, to deoxygenated aqueous solution (5 $\mathrm{mL}$ ) of Cy5-HA-SS-Py conjugate $(50 \mathrm{mg}, 13.55 \mu \mathrm{mol}$ of disulfide pyridyl group) was added DM1 $(29 \mathrm{mg}, 40.5 \mu \mathrm{mol})$ and a catalytic amount of glacial acetic acid in DMSO (13 mL) under nitrogen. The mixture was stirred at $35{ }^{\circ} \mathrm{C}$ for $48 \mathrm{~h}$. Cy5-labeled HA-SS-DM1 prodrug was acquired by extensive dialysis (MWCO 7000) against water/DMSO (1:3, v/v) and then D.I. water followed by lyophilization. Yield: $86 \%$. The amount of DM1 in the Cy5-conjugated HA-SS-DM1 was about $20 w t . \%$.

Preparation of HA-SS-DM1 nanoparticles. HA-SS-DM1 nanoparticles were prepared using solvent exchange method. Typically, $1.2 \mathrm{mg}$ HA-SS-DM1 conjugate was dissolved in water/DMSO mixture $(1 / 1, \mathrm{v} / \mathrm{v})$ overnight under shaking $\left(200 \mathrm{rpm}, 37{ }^{\circ} \mathrm{C}\right)$, followed by extensive dialysis (SPECTRA/POR, MWCO: 3500) against deionized water for $12 \mathrm{~h}$.

Cell Culture. MCF-7 human breast cancer cell line was originated from the cancer center of the Second Affiliated Hospital of Zhejiang University School of Medicine. MCF-7 cells expressed a high level of CD44 receptors, as reported in our previous work ${ }^{2}$. MCF-7 cells were cultured in the DMEM media supplemented with $10 \%$ fetal bovine serum, $1 \%$ L-glutamine, antibiotics penicillin $(100 \mathrm{IU} / \mathrm{mL})$ and streptomycin $(100 \mu \mathrm{g} / \mathrm{mL})$ under $5 \%$ $\mathrm{CO}_{2}$ at $37^{\circ} \mathrm{C}$. 
In Vitro Cytotoxicity Assays. MTT assays were performed as our previous work. Briefly, MCF-7 cells were plated with the cell density of $4 \times 10^{3}$ cells per well in 96-well plates overnight. HA-SS-DM1 prodrug or free DM1 at prescribed DM1 concentrations was added. After $4 \mathrm{~h}$, the medium was replaced and the cells were re-cultured in fresh medium for another 68 h. $20 \mu \mathrm{L}$ of 3-(4,5-dimethylthiazol-2-yl)-2,5-diphenyltetrazolium bromide (MTT) solution $(5 \mathrm{mg} / \mathrm{mL})$ was added to each well. $4 \mathrm{~h}$ later, the supernatant was removed and 150 $\mu \mathrm{L}$ of DMSO was added to dissolve the MTT-formazan crystals. The cell viability (\%) was determined by comparing the absorbance at $490 \mathrm{~nm}$ with control wells containing only cells in culture medium. The inhibitive experiments were conducted by $4 \mathrm{~h}$ pre-treatment of MCF-7 cells with $5 \mathrm{mg} / \mathrm{mL}$ of free HA before adding HA-SS-DM1 prodrug.

Flow Cytometry. MCF-7 cells were seeded in a 6 -well plate at $4 \times 10^{5}$ cells per well in 1 $\mathrm{mL}$ of culture medium overnight. Cy5-labeled HA-SS-DM1 prodrug in $250 \mu \mathrm{L}$ of PBS (Cy5 concentration: $1.0 \mu \mathrm{g} / \mathrm{mL})$ was added. After $4 \mathrm{~h}$, the cells were detached by $0.25 \%(\mathrm{w} / \mathrm{v})$ trypsin and $0.03 \%(\mathrm{w} / \mathrm{v})$ EDTA. The suspensions were centrifuged at $1000 \mathrm{rpm}$ for $3 \mathrm{~min}$ at $4{ }^{\circ} \mathrm{C}$, washed twice with PBS, and then re-suspended in $500 \mu \mathrm{L}$ of PBS. Fluorescence histograms were then recorded with a BD FACS Calibur flow cytometer (Beckton Dickinson, USA). The inhibitive experiments were conducted by $4 \mathrm{~h}$ pre-treatment of MCF- 7 cells with 5 $\mathrm{mg} / \mathrm{mL}$ of free HA before adding HA-SS-DM1 prodrug.

In Vivo Pharmacokinetic Studies. The mice were all handled under protocols approved by Soochow University Laboratory Animal Center and the Animal Care and Use Committee of Soochow University. The pharmacokinetic studies of Cy5-labeled HA-SS-DM1 prodrug were performed in Kunming mice. After administration, the blood samples were collected at $0.083,0.25,0.5,0.75,1,2,4,8,12$, or $24 \mathrm{~h}$ post injection of Cy5-labeled HA-SS-DM1 prodrug $(0.4 \mu \mathrm{g}$ cy5 equiv./mouse). Each blood sample was dissolved in $0.2 \mathrm{~mL}$ of lysis buffer (1\% Triton X-100). Cy5 was extracted by incubating blood samples in $0.5 \mathrm{~mL}$ of DMSO at r.t. for one day. The Cy5 level of the supernatant was determined by fluorescence measurement after centrifugation at $18000 \mathrm{rpm}$ for $20 \mathrm{~min}$. The blood circulation followed a typical two compartment model. The first phase is distribution phase with usually a rapid decline. The second phase is elimination phase with usually a long period, which is the predominant process for drug clearance. We calculated the half lives of two phases $\left(t_{1}\right.$, and $\left.t_{2}\right)$ 
according to the following formula: $y=A_{1} \times \exp \left(-x / t_{1}\right)+A_{2} \times \exp \left(-x / t_{2}\right)+y_{0}$.

H\&E Staining. At the end of the treatment, the mice were sacrificed, and the tumor and major organs including liver, heart, spleen, lung and kidney were excised. The tissues were fixed with $4 \%$ paraformaldehyde solution and embedded in paraffin. The sliced organ tissues (thickness: $4 \mathrm{~mm}$ ) mounted on the glass slides were stained by hematoxylin and eosin (H\&E) and observed by a digital microscope (Leica QWin).

Statistical Analysis. All experiments were performed at least three times and data were expressed as mean \pm S.D. Differences between groups were assessed using the Student's t-test. ${ }^{*} \mathrm{p}<0.05$ was considered significant, and ${ }^{* *} \mathrm{p}<0.01, * * * \mathrm{p}<0.001$ were considered highly significant. 


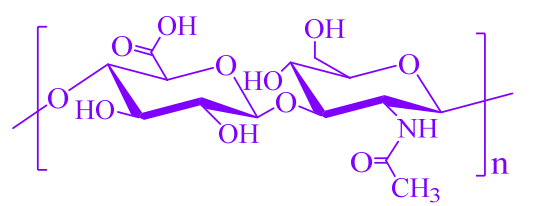

HA $(35 \mathrm{~K})$
$+$<smiles>c1ccc(SCc2cccnc2)nc1</smiles>

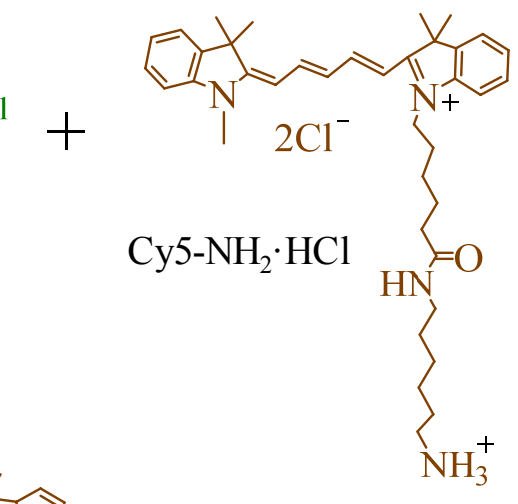

(i) DMTMM, D.I. Water,

$35^{\circ} \mathrm{C}, 24 \mathrm{~h}$

(ii) $\mathrm{DMSO} / \mathrm{PB}$ Buffer, $\mathrm{pH}=6.5,35^{\circ} \mathrm{C}, 48 \mathrm{~h}$

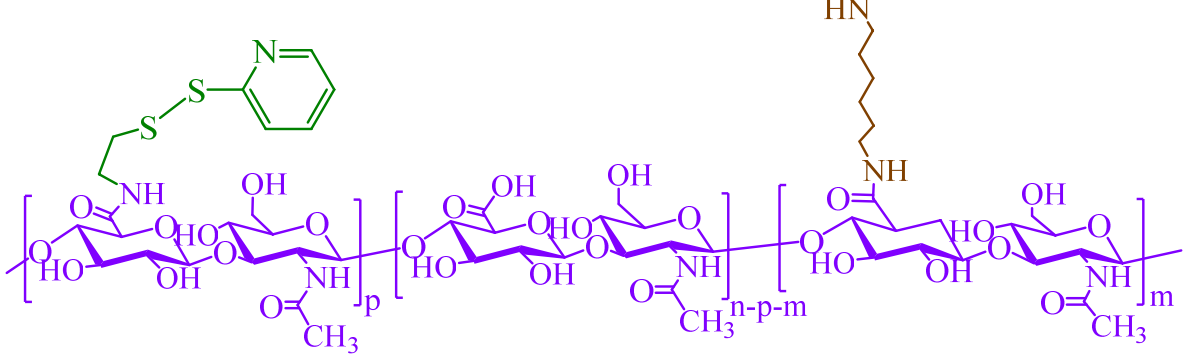

Cy5-labeled HA-SS-Py

(ii)

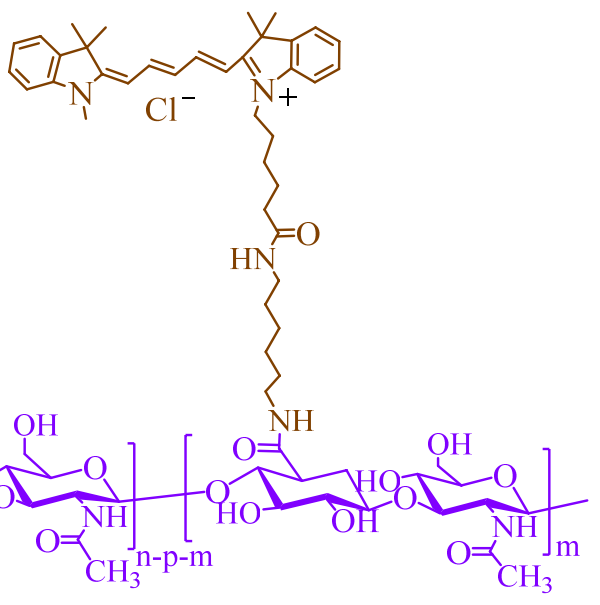

(i)

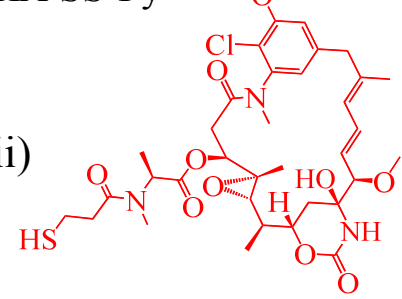

Mertansine (DM1)

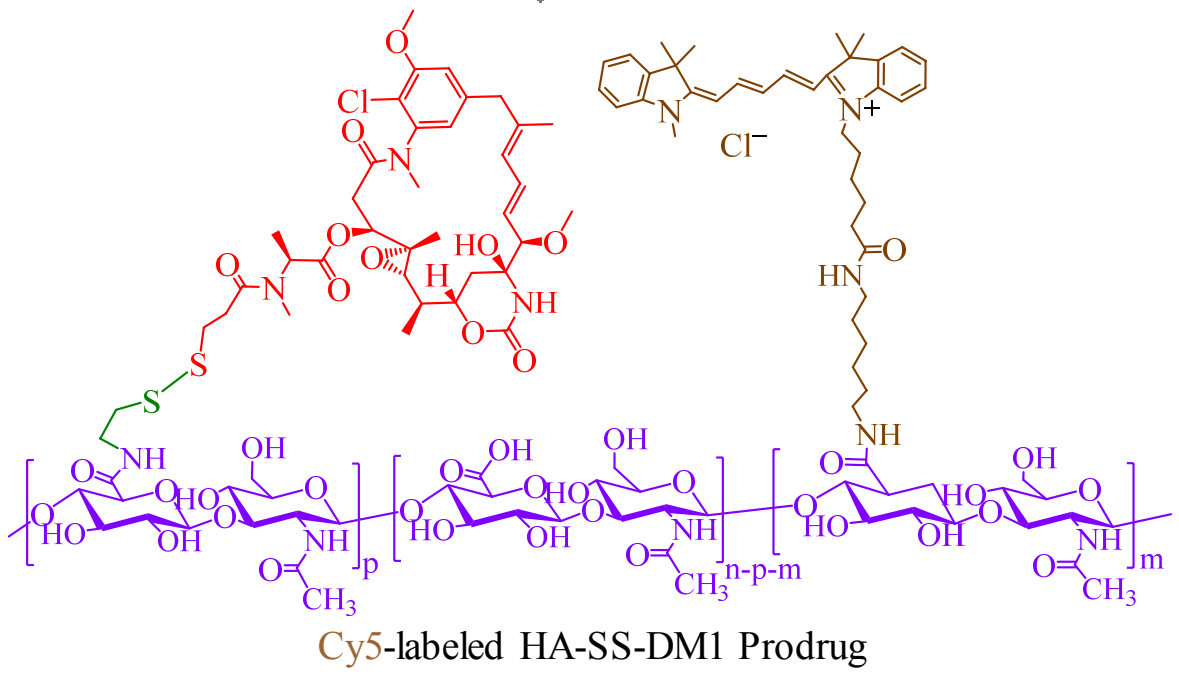

Scheme S1. Synthesis of Cy5-labeled HA-SS-DM1 prodrug. 


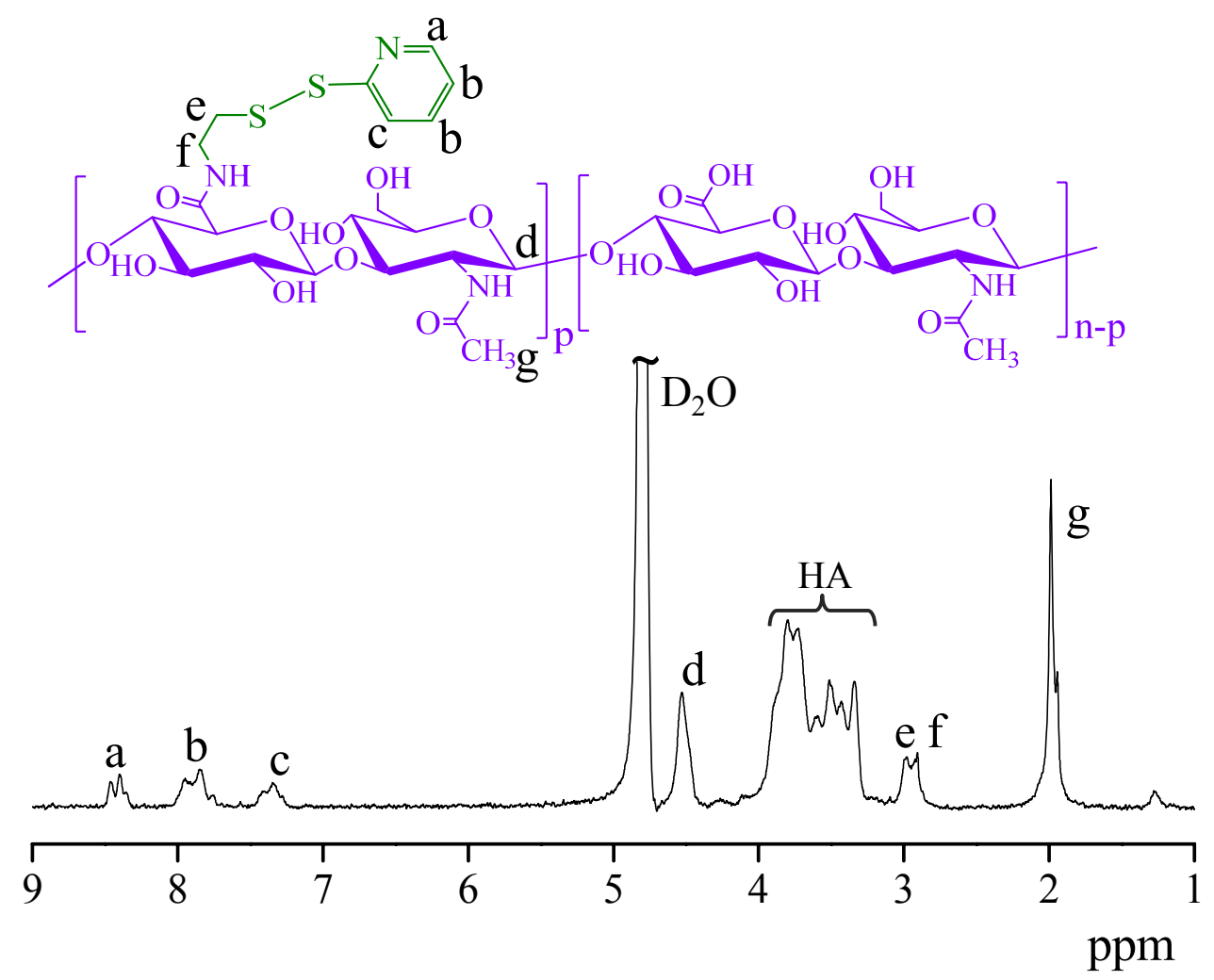

Figure S1. ${ }^{1} \mathrm{H}$ NMR spectrum $\left(400 \mathrm{MHz}, \mathrm{D}_{2} \mathrm{O}\right)$ of HA-SS-Py. 
A

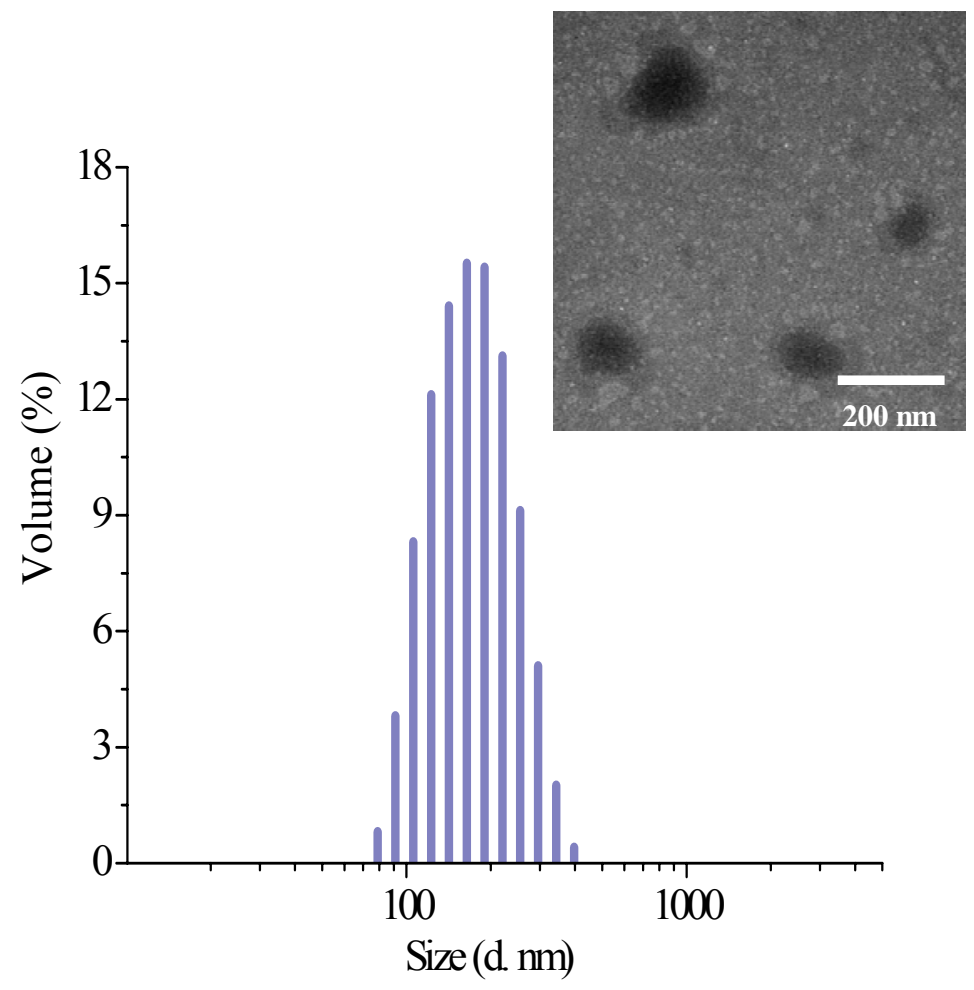

B

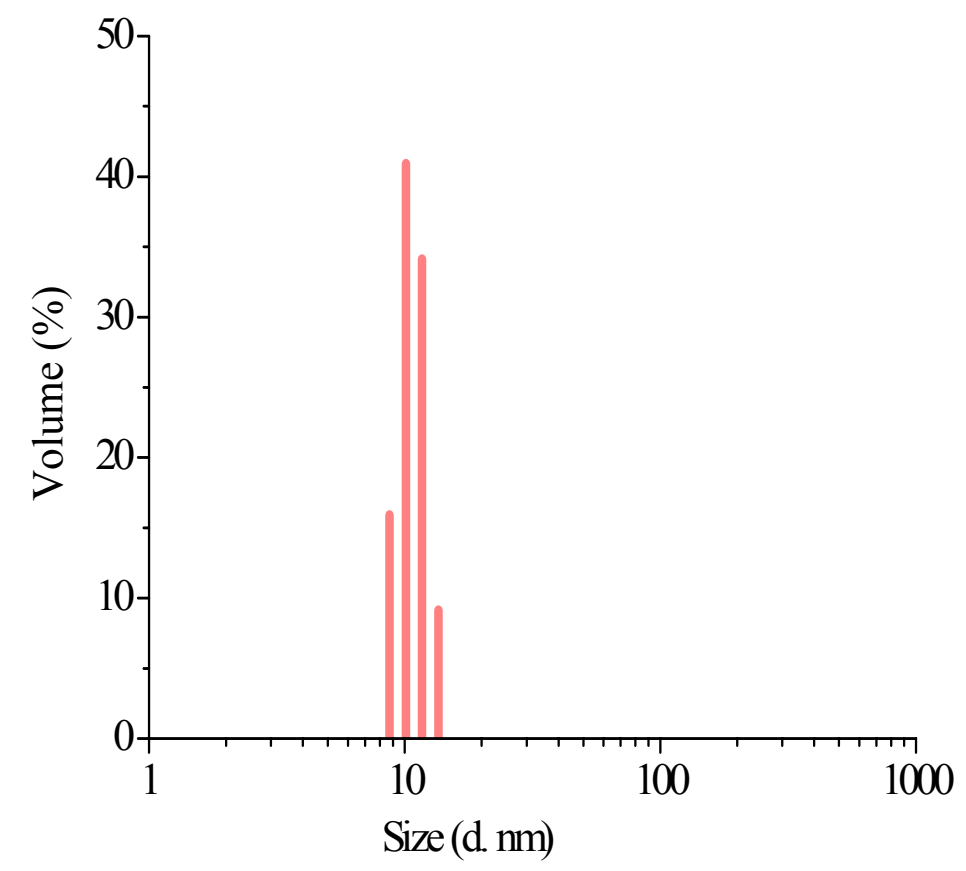

Figure S2. Size and size distribution of HA-SS-DM1 prodrug at $0.2 \mathrm{mg} / \mathrm{mL}$ (A) and $0.04 \mathrm{mg} / \mathrm{mL}$ (B) determined by DLS measurements. The inset in Figure S2A shows the TEM micrograph of HA-SS-DM1 prodrug nanoparticles. 


\section{— HA-SS-DM1 after GSH treatment HA-SS-DM1 Free DM1}
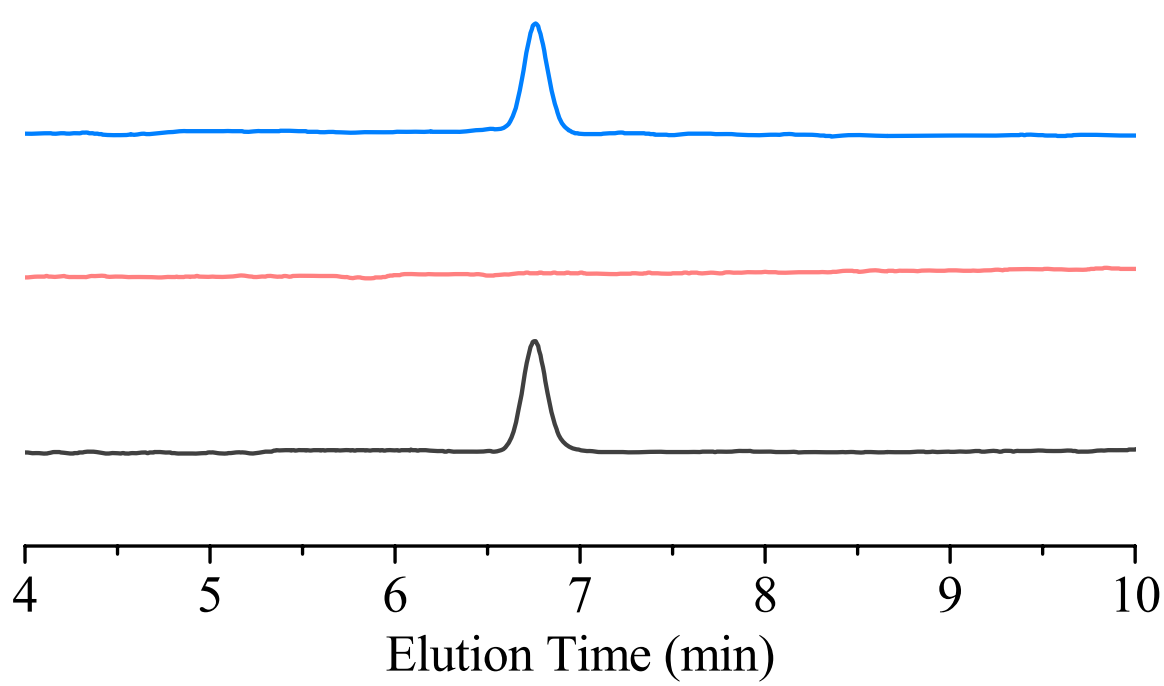

Figure S3. HPLC curves of free DM1, HA-SS-DM1 and HA-SS-DM1 after GSH treatment.
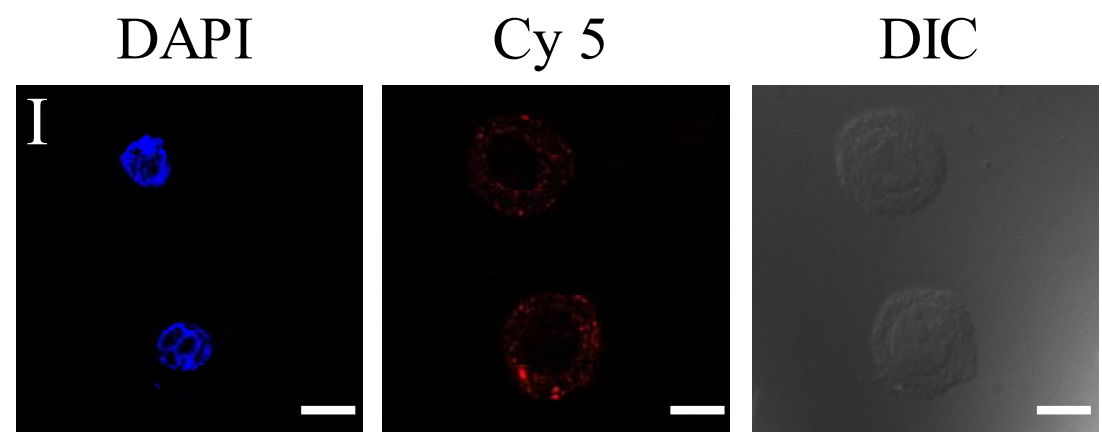

Merged
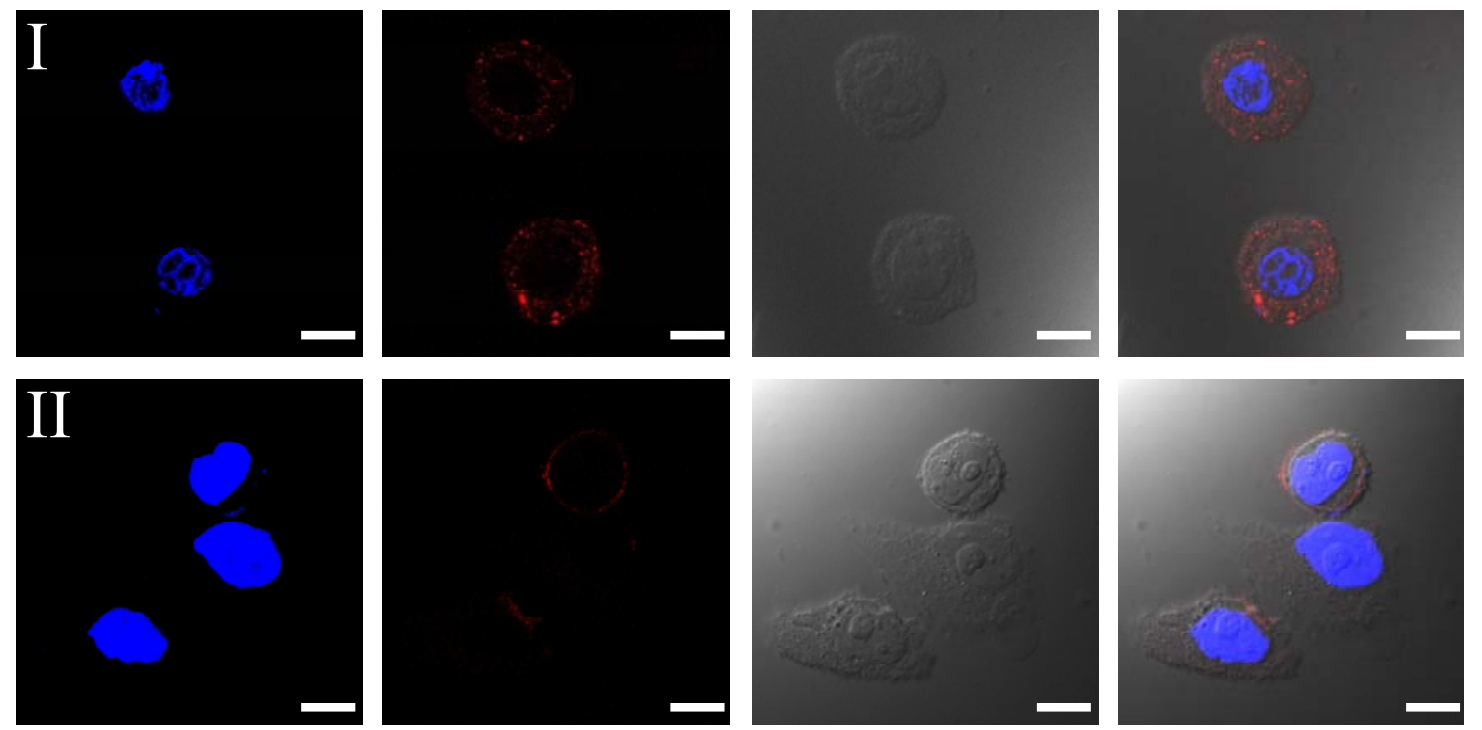

Figure S4. CLSM images of MCF-7 cells after $1 \mathrm{~h}$ culture with Cy5-labeled HA-SS-DM1 at $37{ }^{\circ} \mathrm{C}$ (I) and $4{ }^{\circ} \mathrm{C}$ (II) (scale bar: $10 \mu \mathrm{m}$ ). For each panel, the images from left to right show cell nuclei stained by DAPI (blue), Cy5 fluorescence in MCF-7 cells (red), the differential interference contrast microscopy (DIC) of cells and overlays of the three images. 


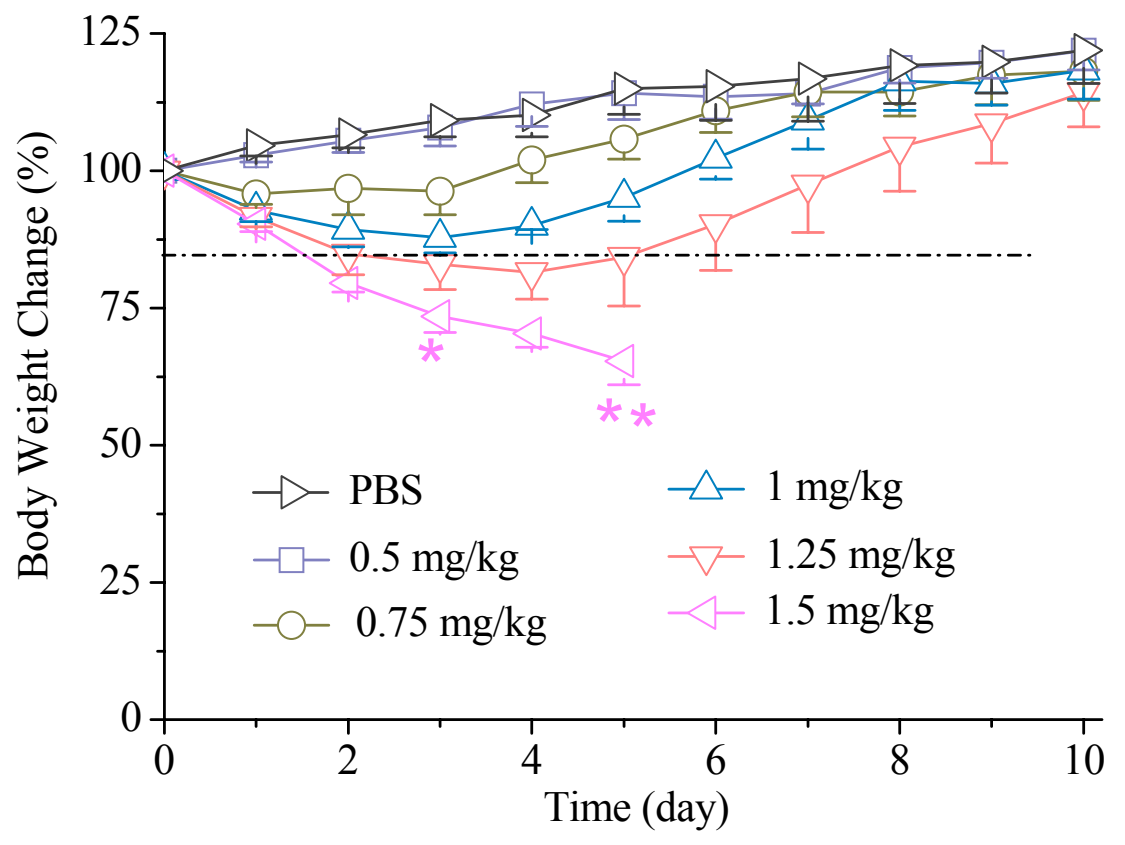

Figure S5. MTD studies of free DM1 in normal mice ( $\mathrm{n}=5)$ (DM1 doses: $0.5,0.75,1,1.25,1.5$ $\mathrm{mg} / \mathrm{kg})$. * indicates that one mouse died.

\section{References}

(1) Zugates, G. T.; Anderson, D. G.; Little, S. R.; Lawhorn, I. E.; Langer, R. J. Am. Chem. Soc. 2006, 128 (39), 12726-12734.

(2) Zhong, Y.; Zhang, J.; Cheng, R.; Deng, C.; Meng, F.; Xie, F.; Zhong, Z. J. Control. Release 2015, 205, 144-154. 